\title{
ANALYSIS OF TRACTION SCRAP APPLICABILITY FOR THE MANUFACTURING OF CARRYING AND CONDUCTING EQUIPMENT DESIGNED FOR OVERHEAD CONTACT LINES
}

\author{
Michał SADZIKOWSKI, Grzegorz KIESIEWICZ, Paweł KWAŚNIEWSKI, Wojciech ŚCIĘŻOR, \\ Paweł STRZĘPEK
}

AGH University of Science and Technology, Cracow, Poland, EU

msa@agh.edu.pl

https://doi.org/10.37904/metal.2019.965

\begin{abstract}
Nowadays the technological progress of the railway transport is characterized by high demand for new material and technological solutions throughout the whole construction whilst taking into account the carrying and conducting traction equipment, which is traditionally manufactured from pure materials via continuous casting and die forging. The current renewal works of the railway trunks carried out all over Europe connected with simultaneous expansion generate large amounts of traction scrap in the form of worn-out carrying ropes and overhead contact lines. Therefore, research work was undertaken in order to develop new recycling technology of the aforementioned scrap into new traction equipment. The first works related to the development of this technology which assumes the use of minimum $80 \%$ of the traction scrap was directed into identifying the occurring impurities on the surface of the tested materials and their direct influence on the final properties of the product. Firstly, the analysis of the thickness of the impurities layer on the surface of carrying ropes and overhead contact lines and the chemical composition analysis with the use of the scanning electron microscope was conducted. The majority of the impurities were oxygen and silicon. In order to investigate the influence of these impurities on the new material obtained from the traction scrap the tested materials were melted and crystallized. A large number of impurities in the copper matrix were detected and they may have a direct impact on the production processes (die forging, supersaturation, artificial aging) of the new carrying and conducting traction equipment.
\end{abstract}

Keywords: Metallurgy, copper, metal scraps, traction scraps, recycling

\section{INTRODUCTION}

Among countries with highly developed economy, including Poland, the rail transport system is one of the most important ways of transportation both public and freight. High exploitation associated with that along with the constant need for improvement of the efficiency of the railway routes creates a continuous need to develop this sector of transportation via the modernization of the existing and building new railway lines. All this combined forces the supply of the new materials for the production of various equipment of the upper traction network, as well as the management of worn elements which are part of the railway network, i.e. carrying ropes and overhead contact lines. Additionally, current Polish railway system has been developed and implemented for operation several decades ago and it was expected to last at least 30 years which also generates the need for its modernization [1-3]. The development of the electrified railway lines over the years has allowed the creation of many traction network systems which produced a large demand for material responsible for transferring electricity to the electric locomotive. Polish railway traction currently in use distinguishes two main components, i.e. the lower traction network and the upper traction network. The lower traction network is built of a system of connected and cooperating elements, i.e. railway tracks with equipment and the substructure of the track. The upper traction network is much more complex as it consists of support structure, suspension systems, overhead contact lines, carrying ropes, tension devices, insulators, suspension cables, elasticizing cables and fastening equipment which ensures efficient cooperation of all the above mentioned elements $[4,5]$. 
The upper traction elements responsible for the electricity transmission to the locomotive are mainly copperbased. Fastening equipment such as various types of wire holders are usually made of brass or bronze rather than pure copper due to their carrying-conducting nature of application. Overhead contact lines, carrying ropes and suspension cables since they are responsible for the supply of the electricity to the locomotive they should be characterised with the highest electrical properties i.e. high electrical conductivity and low electrical resistance [4]. At the University of Science and Technology at Faculty of Non-Ferrous Metals research works were carried out as part of the Innovative Recycling Program entitled "Recycling technology of manufacturing of copper-based fastening equipment dedicated for traction networks" which assume the use of exploited elements of the traction networks for production of the new equipment made of CuNi2Si and CuZn37Ni1Si0.5 alloys. Firstly, this article presents research issues concerning the determination of the impurities present on the surface of the copper scrap of upper traction origin, i.e. carrying ropes and overhead contact lines made of ETP grade copper. Additionally the impact of these impurities on the basic material properties of copper after the melting and crystallization processes will be analyzed as in the future this recycled copper will provide possible charge in the production of modern equipment for the upper traction network. The main goal of this work was to identify the surface impurities generated throughout many years of operation of the upper traction network. In particular, the research program included the analysis of the morphology of impurities on the surface of the carrying ropes and overhead contact lines scrap along with the analysis of their thickness. The second stage of the conducted research involved the analysis of the chemical composition of the traction scrap carried out after the melting and crystallization processes as well as the determination of the basic properties of the material after these processes.

\section{RESEARCH RESULTS AND ANALYSIS}

The conducted research was divided into two parts. Firstly the theoretical analysis was made in order to define the requirements of the materials used for overhead contact lines and carrying ropes which became a reference point (especially in terms of chemical composition) for the second, empirical part which allowed to determine the degree of contamination in the melted traction scrap and its direct impact on the material properties.

\subsection{Material analysis of current applications}

Currently used rules and regulations according to which railway tractions should be built and modernized indicate a group of materials that may be used for particular types of applications. Taking into consideration the internal regulations of the main railroad operator in Poland which is PKP Polskie Linie Kolejowe S.A. (PLK) it is recommended to use ETP grade copper for manufacturing of carrying ropes [6]. All around the world for this type of applications various alloys with the addition of magnesium, silver or cadmium (the last one not so much anymore as it is harmful to environment and living organisms) are used. There are also steel based carrying ropes with copper coating, however, these materials were scarcely used on few routes around the world $[4,7]$.

Considering overhead contact lines on Polish railway routes PLK allows the use of pure electrolytic copper, copper alloys with the addition of silver $(0.1 \mathrm{wt} \%$ of $\mathrm{Ag})$ and copper alloys with the addition of magnesium (from $0.2 \mathrm{wt} \%$ to $0.5 \mathrm{wt} \%$ of $\mathrm{Mg}$ ). Also in this case other alloys may be found around the world, such as copper alloys with cadmium ( $0.7 \mathrm{wt} \%$ to $1 \mathrm{wt} \%$ of $\mathrm{Cd}$ ) or copper alloys with the addition of tin ( $0.2 \mathrm{wt} \%$ of $\mathrm{Sn})$. As indicated above, the main material allowed by the PLK for the production of carrying ropes is ETP grade copper of various construction types, i.e. various current cross-sections. Copper used for the production is a material characterized with high chemical purity and its exact chemical composition is defined in the PN-EN1976 and PN-EN 1977 standards (Table 1). 
Table 1 Chemical composition of Cu-ETP (wt\%) $[12,13]$

\begin{tabular}{|c|c|c|c|c|c|}
\hline $\mathrm{Cu}$ & $\mathrm{Ag}$ & $\mathrm{Bi}$ & 0 & $\mathrm{~Pb}$ & Other \\
\hline Min. & \multicolumn{4}{|c|}{ Max. } & \multirow{2}{*}{$\begin{array}{c}(\mathrm{As}+\mathrm{Bi}+\mathrm{Cd}+\mathrm{Co}+\mathrm{Cr}+\mathrm{Fe}+\mathrm{Mn}+\mathrm{Ni}+\mathrm{P}+\mathrm{Pb}+\mathrm{S}+\mathrm{Sb}+\mathrm{Se}+\mathrm{Si}+ \\
\mathrm{Sn}+\mathrm{Te}+\mathrm{Zn}) \mathrm{Max} .0 .03\end{array}$} \\
\hline 99.90 & 0.015 & 0.0005 & 0.040 & 0.0005 & \\
\hline
\end{tabular}

Considering Polish railway routes PLK allows the use of various alloys for the manufacturing of overhead contact lines. Apart from ETP grade copper alloys like CuAg0.1, CuMg0.2 or CuMg0.5 are allowed. Taking into account the scheduled research concerning the possibility of using the traction scrap as charge material for manufacturing the equipment made of CuNi2Si and CuZn37Ni1Si0.5 alloys, the most interesting material is pure copper. Its standardized chemical composition (Table 1) allows the total amount of impurities in the material not larger than 300 ppm and distinguishes the allowable content of elements such as lead (5 ppm), bismuth (5 ppm), silver (150 ppm) and oxygen level that does not exceed 400 ppm. In the case of the domestic railway transport the requirements are even stricter and distinguish more elements and their maximum values that may contaminate the alloy out of which the overhead contact lines are manufactured (Table 2).

Table 2 Requirements concerning chemical composition for specific material applications according to PLK [9]

\begin{tabular}{|c|c|c|c|c|c|c|c|c|c|c|c|c|c|c|}
\hline \multirow{3}{*}{ Grade } & \multicolumn{14}{|c|}{ Chemical composition (wt \%) } \\
\hline & \multicolumn{2}{|c|}{$\begin{array}{l}\text { Modifiers' } \\
\text { content * }\end{array}$} & \multicolumn{11}{|c|}{ Allowable content of impurities } & \multirow{2}{*}{$\mathrm{Cu}$} \\
\hline & $\mathrm{Ag}$ & Mg & Sn & $\mathrm{Ni}$ & $\mathbf{B i}$ & $\mathrm{Pb}$ & $\mathrm{Sb}$ & As & $\mathrm{Fe}$ & $\mathrm{Zn}$ & $\mathbf{s}$ & $\mathbf{0}$ & Other & \\
\hline $\mathrm{Cu}$ - ETP & - & - & 0.002 & 0.002 & 0.001 & 0.005 & 0.002 & 0.002 & 0.005 & 0.003 & 0.004 & 0.04 & - & \multirow{4}{*}{ 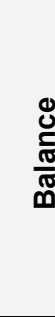 } \\
\hline CuAg0.1 & $\begin{array}{c}0.08- \\
0.12 \\
\end{array}$ & - & - & - & - & - & - & - & - & - & - & 0.04 & 0.03 & \\
\hline CuMg0.2 & - & $\begin{array}{l}0.1- \\
0.3\end{array}$ & - & - & - & - & - & - & - & - & - & - & 0.1 & \\
\hline CuMg0.5 & - & $\begin{array}{l}0.4- \\
0.7\end{array}$ & - & - & - & - & - & - & - & - & - & - & 0.1 & \\
\hline
\end{tabular}

\subsection{Research on the surface impurities of the traction scrap}

Research was carried out on the copper scrap obtained from the carrying ropes and overhead contact lines of ETP grade from worn upper traction which precise origin is unknown (Figure 1). Carrying ropes and overhead contact lines' scrap were characterized by total contamination of the surface with various types of grease and dust.

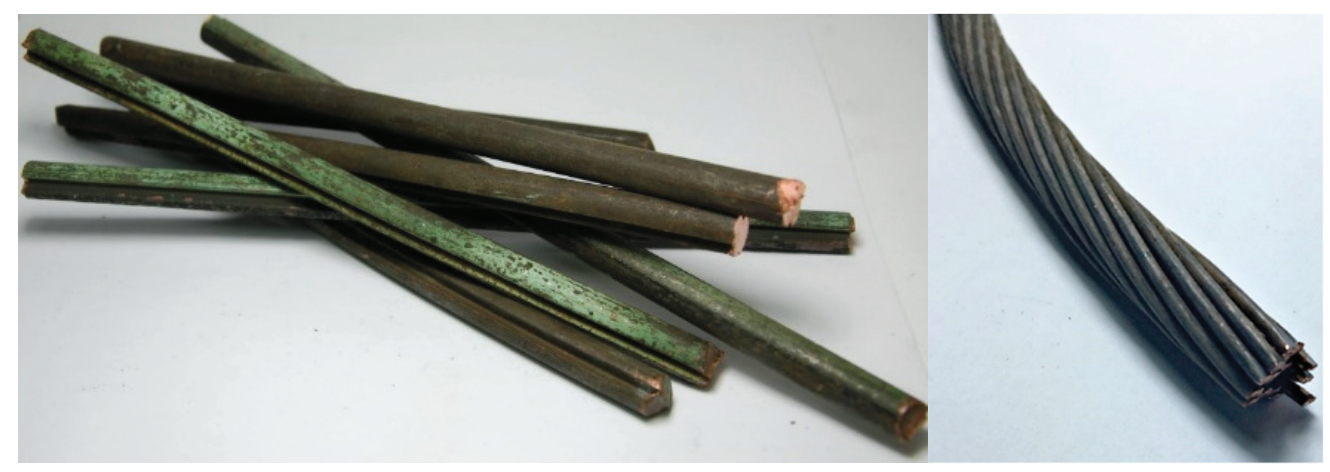

Figure 1 Overhead contact line scraps (on the left) and carrying rope scraps (on the right) used during research 
Firstly, the surface analysis with the use of scanning electron microscope Hitachi SU-70 was carried out which allowed the observation of the surface topography and the analysis of its chemical composition. From each type of material, samples were selected for the observations of impurities. Observation with the SE signal of the area lying close to the surface of the sample distinctly reflected the surface topography whereas the image with various magnifications revealed the surface impurities of the selected representative samples (Figure 2).
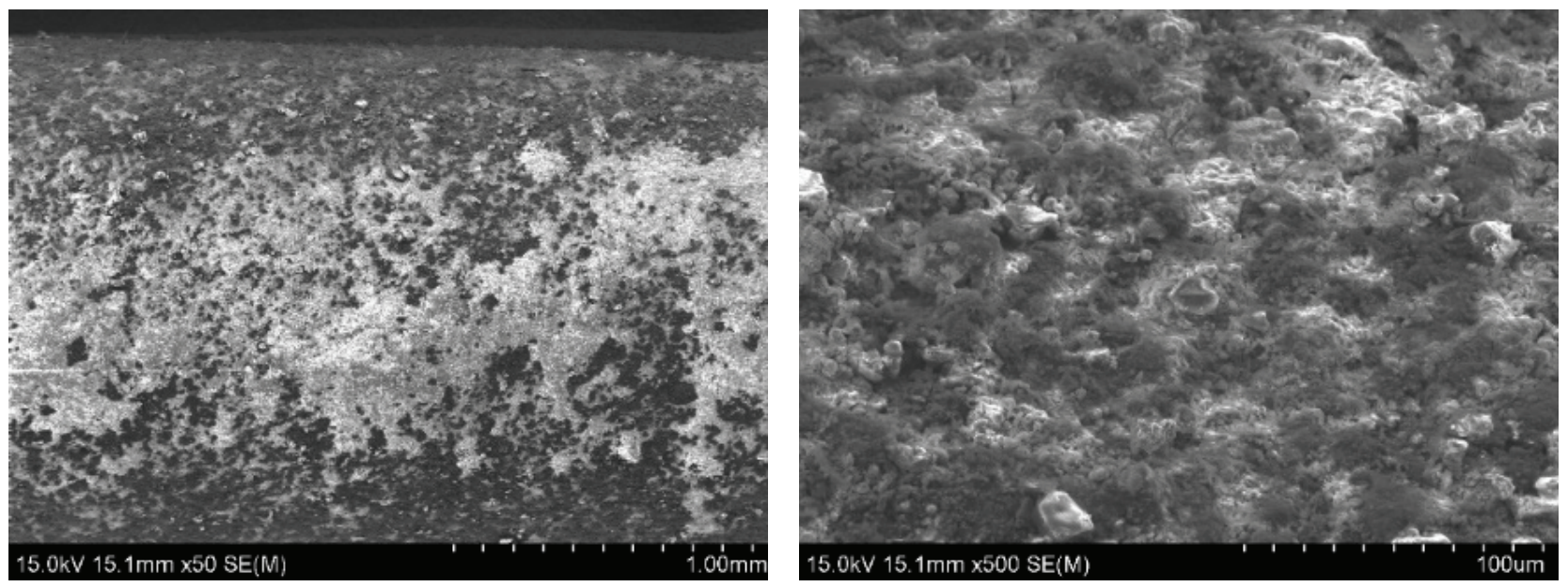

Figure 2 Exemplary surface of the carrying rope analysis in terms of the surface impurities

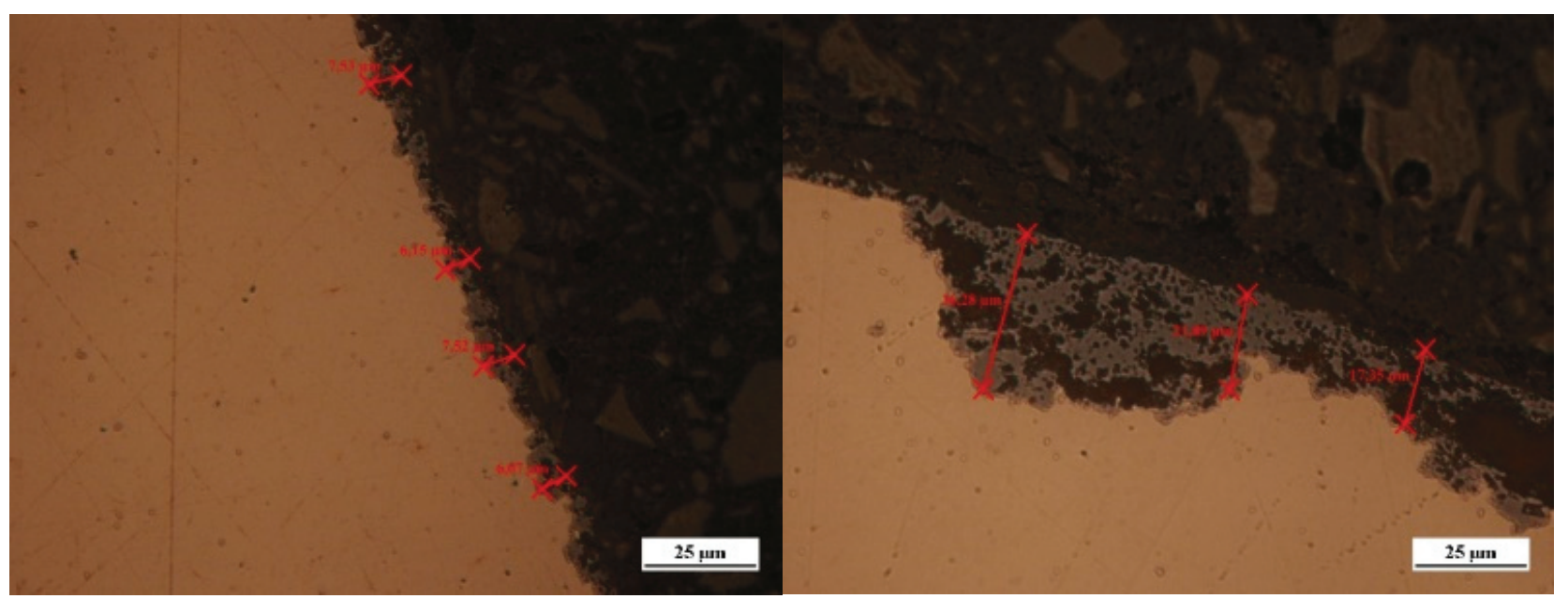

Figure 3 The measurement of the impurities' thickness on the surface of the carrying rope's samples

The analysis of the chemical composition of the surface was conducted using the EDX detector. Due to the varied degree of impurities in the materials the measurement was carried out in the variable areas of the samples. The conducted analysis of the chemical composition revealed clusters of various impurities which were mostly found on both types of samples. The largest amount of surface impurities detected during the analysis of carrying ropes were, undoubtedly, the molecules of oxygen which could most likely form various types of oxide compounds with base material on the tested surfaces. In both cases, i.e. the carrying ropes and the overhead contact lines surface impurities with such elements were also noted: aluminum, silicon, calcium, iron, phosphorus, fluorine and magnesium. The analysis of the surface morphology of the overhead contact lines showed that again the larges amount of impurities were of oxygen origin. It should be noted that on the surface of the analyzed overhead contact lines such elements as titanium or potassium were also observed which were not detected on the scrap surface of the carrying ropes. The next part of the conducted research was to determine the thickness of the impurities on the surface of traction scrap. The Olympus GX51 optical 
microscope was used to determine that. The thickness of the impurities visible during the optical microscope observations of the carrying ropes ranges from approx. 3 to $18 \mu \mathrm{m}$. Additionally, the loss of material in the accumulation place of impurities has been observed on the surface (Figure 3). The analysis of the thickness of impurities on the surface of the overhead contact line has confirmed that the thickest layer of impurities is present in the groove and is equal to approx. $16 \mu \mathrm{m}$ which is in direct correlation with the highest amount of impurities identified during scanning electron microscope analysis. On the operating part of the material the layer of impurities is the thinnest as is equal to approx. $5 \mu \mathrm{m}$. The thickness of the impurities in other parts of the material ranges from $5 \mu \mathrm{m}$ to $10 \mu \mathrm{m}$.

\subsection{Research on the melting and crystallization processes of metal scrap}

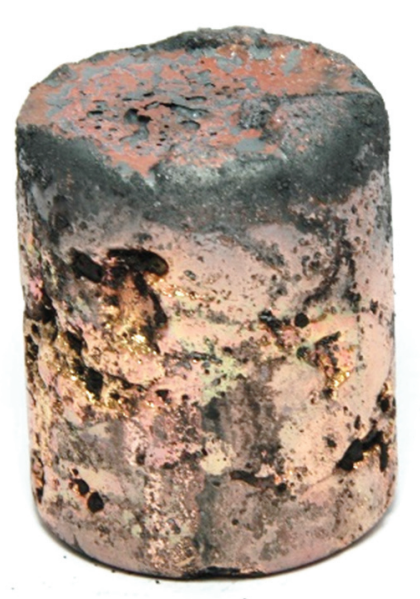

Figure 4 Ingot casted at the $1150{ }^{\circ} \mathrm{C}$ using scraps of the overhead contact lines

In order to identify the possibility of the commercial use of scrap from the upper traction, preliminary metallurgical tests were carried out which objective was to determine the degree of contamination of the material after the melting and crystallization processes. The research program assumed the melting of the material in the resistance furnace at $1150^{\circ} \mathrm{C}$ for one hour starting from the moment the liquid metal was obtained. The charge with an initial weight of about $450 \mathrm{~g}$ was melted in high-quality graphite isostatically pressed crucibles of type R4550 and the surface of the molten material was covered with flake graphite to deoxidize copper, as well as to remove metal oxides impurities formed during the melting process. Ingots after being removed from the furnace in a selected time schedule were additionally stirred with a graphite rod and after the crystallization process was completed they were allowed to cool down freely at ambient temperature. The obtained ingots were characterized by relatively high porosity and surface discontinuity (Figure 4).

The final product of scrap melting was not only solid metal, but also large amounts of melting losses and ashes formed most likely due to the precipitation of a large amount of impurities from liquid metal. The chemical composition analysis carried out on the Foundry-Master Xpert optical spark emission spectrometer and the basic properties tests of melted scrap helped to reveal the actual state of the material after metallurgical processes. The analysis of the chemical composition conducted on the longitudinal section of the cut ingot allowed to analyze the accumulation of impurities in its volume. The obtained results showed that ingots were usually characterized with a similar content of impurities throughout their entire volume, and only in some cases there was a greater accumulation of impurities within the shrink hole or the lower part of the ingot. The impurities of the ingots manufactured from carrying ropes and overhead contact lines were more or less the same and the maximum value of impurities highly exceeded the standardized values. In the case of carrying ropes, such elements as lead, manganese, iron, silicon, chromium, aluminum, sulfur, arsenic, cobalt, antimony and tellurium were detected. The highest concentration was characterized by antimony in the amount of 0.012 wt $\%$ and iron in an amount of $0.0115 \mathrm{wt} \%$, also a large amount of manganese, silicon and aluminum were observed at about $0.009 \mathrm{wt} \%$. The allowable total content of impurities in ETP grade copper should not exceed $0.03 \mathrm{wt} \%$, unfortunately in this case the impurities value is exceeded almost three times. This suggests the need to take extra steps to apply various methods of purifying this type of batch material. The exact distribution of the remaining impurities found in the volume of the ingot is shown in Figure 5.

The obtained from the overhead contact line scrap ingots were characterized with a slightly higher amount of impurities than in the previously discussed case. In the analyzed material the allowable impurities content was again exceeded over three times. The ingots obtained from the melted overhead contact lines were characterized with the same impurities as the ones made from carrying ropes. The only exception was tin in the amount of $0.0077 \mathrm{wt} \%$ zero amount of lead. Similarly to the case of the ingots made of carrying ropes the 
impurities with the highest amount were manganese (0.0107 wt \%), iron (0.0122 wt\%), silicon (0.0091 wt\%), aluminum $(0.0136 \mathrm{wt} \%)$ and antimony $(0.0102 \mathrm{wt} \%)$. Also in the case of ingots made of the overhead contact lines, all other impurities elements detected exceed more or less their allowable concentrations in relation to the relevant standardized values. The total distribution of impurities elements in a casted ingot from worn overhead contact lines is shown in Figure 6.

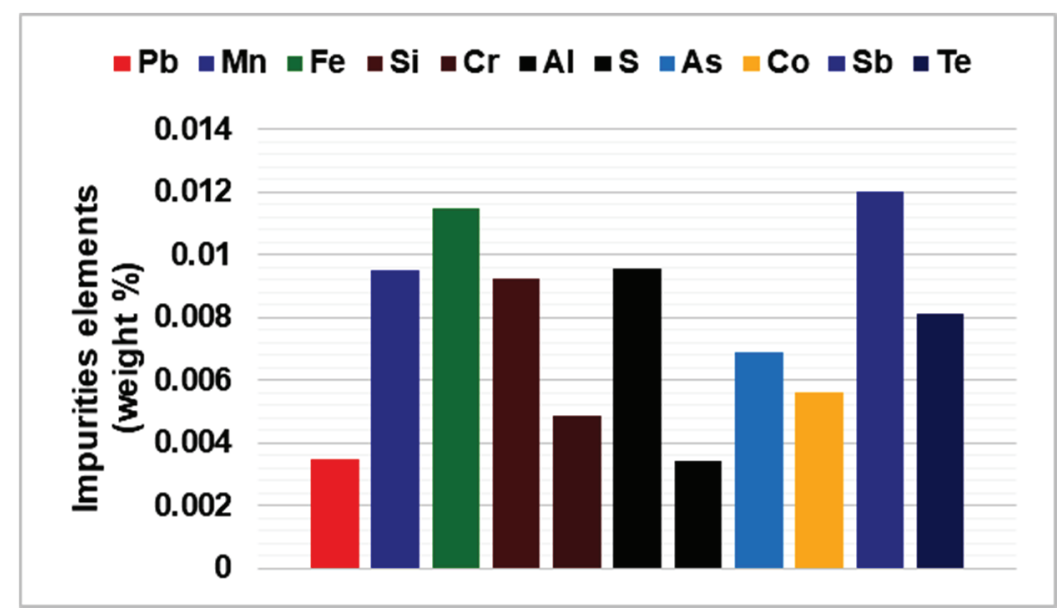

Figure 5 Impurities occurring at the material after the metallurgical synthesis process of the carrying ropes

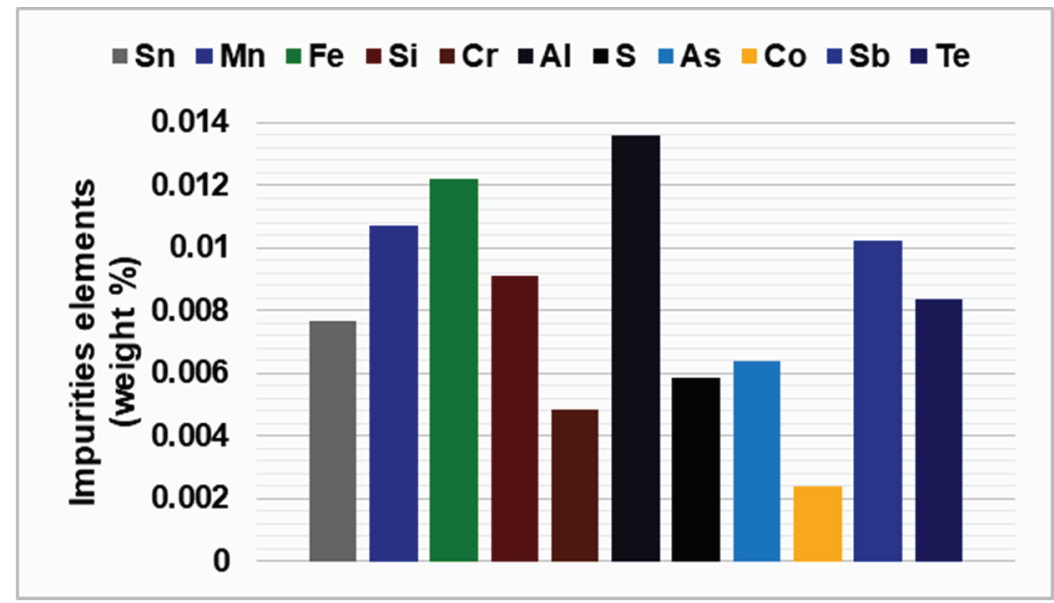

Figure 6 Impurities occurring at the material after the metallurgical synthesis process of the overhead contact lines

The hardness tests using Brinell scale were conducted and the values for the ingots obtained from carrying ropes were around $46.2 \mathrm{HB}$ and in the case of the ingots obtained from the overhead contact lines were around 46.8 HB. These values prove a slightly higher amount of the impurities in the copper matrix in the case of the melted overhead contact lines. Electrical conductivity of the ingots made of worn carrying ropes was measured at $54.5 \mathrm{MS} / \mathrm{m}$ and in the case of the ingots made of the overhead contact lines scrap it is $53.9 \mathrm{MS} / \mathrm{m}$.

\section{CONCLUSION}

The analysis of the obtained results of the chemical composition analysis and basic properties tests of the ingots shows that it is necessary to purify this type of scrap before re-use. The material obtained in the processing of carrying ropes and overhead contact lines scrap due to its diverse chemical composition may in practice cause various difficulties related to further processing stages, i.e. the forging process with saturation 
on the press and the susceptibility to the artificial aging process. These conclusions were drawn on the basis of exceeded total accumulations of impurities in the ingot made of the carrying ropes almost three times, and in the case of the overhead contact lines over three times in comparison to the standardized values of ETP grade copper. Additionally, the chemical composition analysis showed that all elements identified in the ingots made of the overhead contact lines scrap have exceeded the allowable standards. Antimony which was one of the largest impurities in these ingots was defined in the standards as an acceptable impurity if not exceeding $0.002 \mathrm{wt} \%$, and the obtained analyzes show that it exceeds its allowable value almost 6 times for the material made from worn carrying ropes and 3 times for material made from overhead contact line scrap. In the case of the second most-frequent impurity in the ingots, i.e. iron, the lowest value was $0.0115 \mathrm{wt} \%$ whereas the standard only allows the presence of this metal in the amount of $0.005 \mathrm{wt} \%$. Taking into consideration the high amount of the surface impurities of the examined scrap, it seems beneficial to introduce an additional purifying step in the treatment of scrap prior to their melting and crystallization processes. The impurities in the material directly influence its basic properties. The high amount of impurities in the material is clearly visible in the lower value of electrical conductivity as the standardized value of the ETP grade copper is $58 \mathrm{MS} / \mathrm{m}$ whereas the measured value of the ingots made of worn carrying ropes was measured at $54.5 \mathrm{MS} / \mathrm{m}$ and in the case of the ingots made of the overhead contact lines scrap it is $53.9 \mathrm{MS} / \mathrm{m}$ which gives approx. $3.5-4.1 \mathrm{MS} / \mathrm{s}$ difference. The studies carried out and presented in the article constitute the first guidelines for the designing of a new type of technology enabling the use minimum of $80 \%$ of the traction scrap for the production of modern bearing and conducting equipment made of CuNi2Si and CuZn37Ni1Si0.5 alloys.

\section{REFERENCES}

[1] KOZŁOWSKA, M. Demand among the passenger rail market within European Union. Rail transport technology. 2017. no. 1-2, pp. 18-23.

[2] PKP PLK S.A. Equipment of traction network. Standardized document 01-1/ET/2008, PKP PLK S.A. The energetics office, Warsaw, 2008.

[3] KNYCH, T., KAWECKI, A., KWAŚNIEWSKI, P., MAMALA, A. and KIESIEWICZ, G. Laboratory research on the bearing and conducting elements and their cooperation with the equipment intended for traction networks characterized by high mechanical properties and electrical carrying capacity. Rail transport technology. 2010. no. 5-6, pp. 75-80.

[4] KWAŚNIEWSKI, P. Bearing and conducting equipment of the upper railway traction network. Cracow. Publisher Wzorek. 2016. p. 255.

[5] KIESIEWICZ, G. Modern rail suspensions of the upper traction network systems. Cracow. Publisher Impuls. 2018. p. 210.

[6] PKP PLK S.A. Conducting lines (multiwire conducting lines with no insulation). Standardized document 014/ET/2008, PKP PLK S.A. The energetics office, Warsaw, 2008.

[7] ROSTKOWSKI, W. The review of the construction of the traction network among the European Union countries. Rail transport technology. 2006. no. 4, pp. 52-59.

[8] PN-EN 50149:2012, Domestic solutions - stationary installations - electrical traction network - Profiled contact wires made of copper and its alloys

[9] PKP PLK S.A., Profiled contact wires. Standardized document 01-3/ET/2008, PKP PLK S.A. The energetics office, Warsaw, 2008.

[10 KAWECKI, A. Cu-Ag wires of high mechanical properties and high electrical conductivity. Cracow. Publisher Wzorek. 2013. p. 186.

[11] MACIOŁEK, T. The various aspects of designing the high speed railway traction. Rail transport technology. 2012. no. 10 , pp. 31-33.

[12] PN-EN 1976:2013-04 Copper and its alloys - cast materials with no plastic working.

[13] PN-EN 1977:2013-06 Copper and its alloys - batch material for the drawing process of copper (wire rod). 